\title{
ASSESSMENT AND COMPARISION OF GONIAL ANGLE IN PANORAMIC RADIOGRAPH AND LATERAL CEPHALOGRAM IN ADULT PATIENT WITH CLASS I AND CLASS II MALOCCLUSION
}

\author{
Dr. Harish Atram ${ }^{1}$, Dr.Kalyani Chaudhari ${ }^{2}$,Dr. Pankaj Akhare ${ }^{3}$, Dr. Pratik Jaltare ${ }^{4}$, Dr. Akanksha Kumar ${ }^{4}$, \\ Dr. Kshitij Sabley ${ }^{4}$
}

1-Reader and Guide, 2- Postgraduate Student, 3- Professor and HOD, 4- Senior Lecturer, Department Of Orthodontics and Dentofacial Orthopaedics, Swargiya Dadasaheb Kalmegh Smruti Dental College and Hospital, Nagpur

\section{ABSTRACT}

Objective: To assess and compare the Gonial angle from Cephalograms and Orthopantograms of patients with Class I and Class II malocclusion. Material and method: A sample of 50 subjects having Class I and Class II malocclusion was selected from patients reporting to Department of Orthodontics and Dentofacial Orthopaedics. The pre-orthodontics treatment lateral cephalogram and orthopantomogram were used to evaluate the Gonial angle for each subject and also to compare the Gonial angle in Class I and Class II malocclusion. Results: In the present study the mean gonial angle by lateral cephalograom was $127 \pm 7.39$ and by Orthopantomogram it was $123.24 \pm 7.77$ in Class I malocclusion. No statistically significant difference was found mean gonial angle by lateral cephalogram and orthopantomogram.

Conclusion: No statistically significant difference was observed between the gonial angle measured using lateral cephalogram and that determined using the panoramic radiographs. Further there no is statistically significant difference between gonial angle in Class I and Class II malocclusion.

KEYWORDS: Cephalogram, Gonial Angle, Orthopantomogram

\section{INTRODUCTION}

Orthodontic diagnosis and treatment planning involves detailed study of dental occlusion, hard tissue relationships and soft tissue proportions. ${ }^{1}$ The orthodontic diagnosis database is derived from three major sources: History, clinical examination and evaluation of diagnostic records including dental casts, radiographs and photographs.

Cephalograms and orthopantomogram (OPG) are routinely taken for every orthodontic patient. The goal of Cephalometric analysis is to evaluate the horizontal and vertical relationship of five major functional components of the face: The cranium and cranial base, skeletal maxilla, skeletal mandible, the maxillary dentition and alveolar process and the mandibular dentition and alveolar process and the mandibular dentition and alveolar process.

Gonial angle is an important angle of the craniofacial complex. It is significant for the diagnosis of craniofacial disorders. It is one of the important parameters giving an indication regarding the vertical parameters and symmetry of the facial skeleton. The gonial angle is measured by taking 
the tangent to the posterior border of the ramus and tangent to the lower border of the mandible. ${ }^{1}$ The gonial angle depicts the form and shape of the mandible, has a pivotal role in forecasting future mandibular growth, and has certain effects on the profile, changes, growth and position of the mandibular anterior teeth. ${ }^{2}$

Panoramic radiography is frequently used in orthodontic practice to provide important information about the teeth and their axial inclinations, maturation periods and surrounding tissues. $^{3-5}$

Panoramic X-ray technology is commonly accessible and is used in daily clinical routine to assess mandibular vital structures bilaterally. Panoramic radiography allows the visualization of right and left sides of craniofacial structures by producing an accurate, predictable image of all the teeth and related structures in the shortest possible time, with the least amount of radiation to the patient and to the operator. ${ }^{6}$

Shahabi et al. also concluded that panoramic radiography can be used to determine the gonial angle as accurately as a lateral cephalogram. They also mentioned that, in panoramic radiography, the right and left gonial angles can be measured easily without superimposition of anatomic landmarks, which occur frequently in lateral cephalograms. ${ }^{4}$

At present, lateral cephalograms are used for determining gonial angle and Frankfurt mandibular angle; however, in this method, measuring individual gonial angle becomes difficult due to the superimposed images of anatomical structures in a lateral cephalogram. However, panoramic images have the advantage of reduced superimposition of anatomical structures. ${ }^{6} \quad$ Studies examining panoramic radiographs as means of investigating skeletal patterns are lacking in the orthodontics literature. OPG, which is used as an essential diagnostic aid can be used for reliable measurement of gonial angle as there is no complication of super- imposed images appearing as a cephalograms.

\section{MATERIAL AND METHOD}

In this study, pretreatment lateral cephalogram of total 50 subjects with Angle Class I and Class II malocclusion patients were taken from the records of patients undergoing orthodontic treatment in Department of Orthodontics and Dentofacial Orthopaedics. All these radiographs were taken with a digital panoramic system under standard exposure factors, as recommended by the manufacturer.

Patients with Class I and Class II malocclusion, high quality radiographs with adequate sharpness were taken by the same apparatus and in a natural head position are included in the study and patients with a previous history of facial or mandibular surgery or syndromes affecting the jaw or face, patients with Class III malocclusion were excluded.

The gonial angle was determined by drawing the tangent of the lower border of the mandible and the distal border of the ascending ramus and the condyle on both Cephalometric and panoramic radiographs (Figures I and II). The magnification factor used for the machine was 1.15.

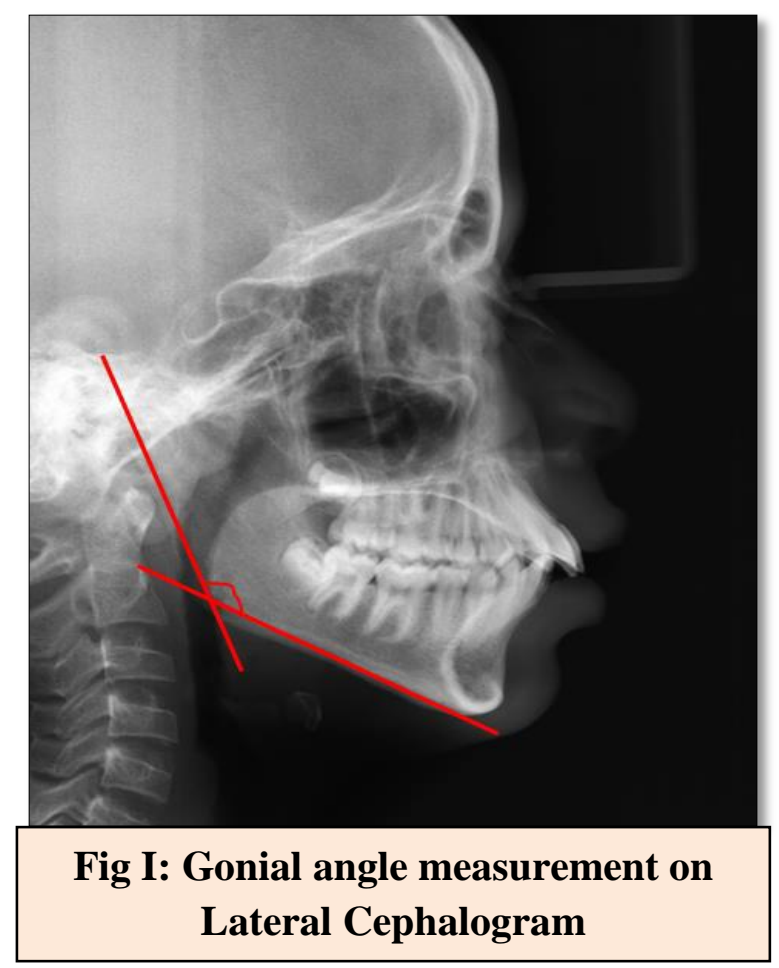




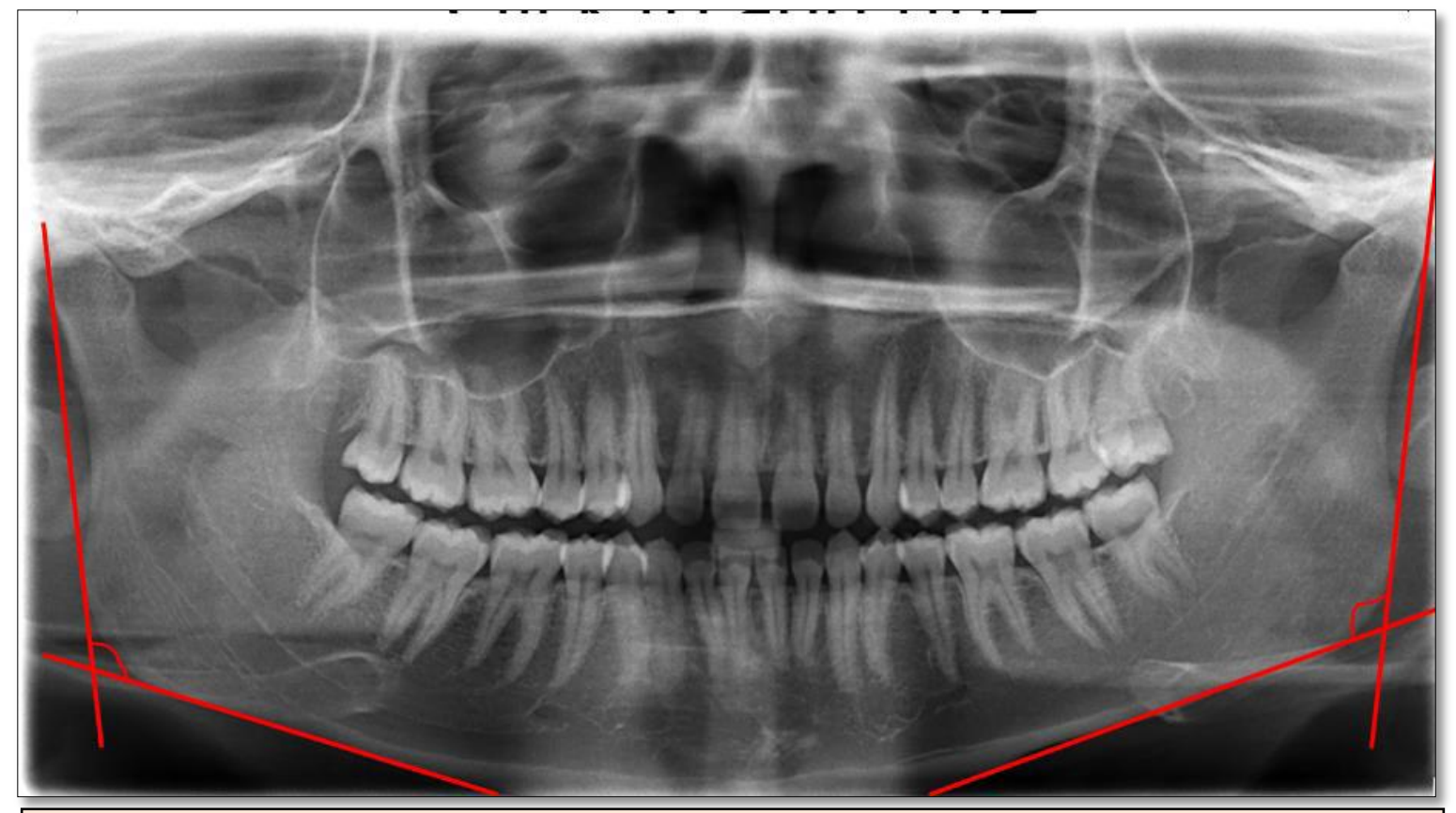

Fig II: Gonial angle measurement on Orthopantomogram (OPG)

\section{STATISTICAL ANALYSIS}

Assessing the reliability of gonial angle in panoramic radiograph compared to lateral cephalogram in adult patient with Class I and Class II Malocclusion was done using descriptive and inferential statistics using Student's paired t test and unpaired t test and software used in the analysis was SPSS 24.0 version and $p<0.05$ is considered as level of significance.

\section{RESULTS}

In the present study, the comparision of gonial angle in panoramic radiograph and lateral cephalogram in adult patient with Class I and Class II Malocclusion is obtained from the radiographs of 50 subjects it shows Mean gonial angle by lateral cephalograom was $127 \pm 7.39$ and by Orthopantomogram it was $123.24 \pm 7.77$. By using Student's paired $t$ test statistically significant difference was found mean gonial angle by lateral cephalogram and orthopantomogram $(t=4.73, p=0.0001)$. [Table I, Graph I]

\begin{tabular}{|c|c|c|c|c|c|c|}
\hline \\
Table I: Comparison of Gonial angle in Lateral Cephalogram and Orthopantomogram in Class I \\
malocclusion \\
& Mean & $\mathbf{N}$ & $\begin{array}{c}\text { Std. } \\
\text { Deviation }\end{array}$ & $\begin{array}{c}\text { Std. Error } \\
\text { Mean }\end{array}$ & $\begin{array}{c}\text { Mean } \\
\text { Difference }\end{array}$ & t-value \\
$\begin{array}{c}\text { Lateral } \\
\text { Cephalogram }\end{array}$ & 127.00 & 25 & 7.39 & 1.47 & & 4.73 \\
Orthopantomogram & 123.24 & 25 & 7.77 & 1.55 & & $\mathrm{p}=0.0001, \mathrm{~S}$ \\
\hline
\end{tabular}


Graph I: Comparison of Gonial angle in Lateral Cephalogram and OPG in Class I malocclusion

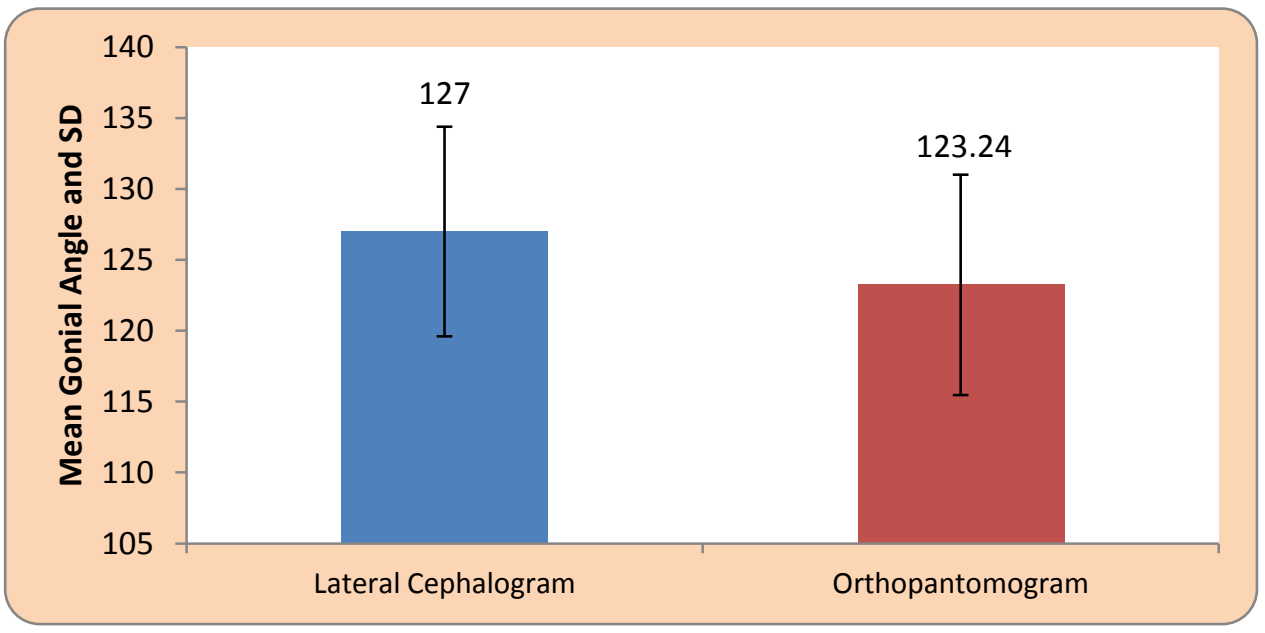

Mean gonial angle by lateral cephalograom was $124.80 \pm 3.56$ and by Orthopantomogram it was

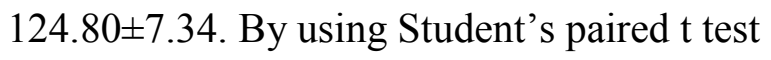

statistically no significant difference was found mean gonial angle by lateral cephalogram and orthopantogram $(t=0, p=1.00)$.[Table II, Graph II]

Table II : Comparison of Gonial angle in Lateral Cephalogram and OPG in Class II malocclusion

\begin{tabular}{|c|c|c|c|c|c|c|}
\hline & Mean & N & SD & $\begin{array}{c}\text { Std. Error } \\
\text { Mean }\end{array}$ & $\begin{array}{c}\text { Mean } \\
\text { Difference }\end{array}$ & t-value \\
$\begin{array}{c}\text { Lateral } \\
\text { Cephalogram }\end{array}$ & 124.80 & 25 & 3.56 & 0.71 & \multirow{2}{*}{$0 \pm 0$} & 0 \\
\cline { 1 - 4 } Orthopantomogram & 124.80 & 25 & 7.34 & 1.46 & & $00, \mathrm{NS}$ \\
\hline
\end{tabular}

Graph II : Comparison of Gonial angle in Lateral Cephalogram and OPG in Class II malocclusion

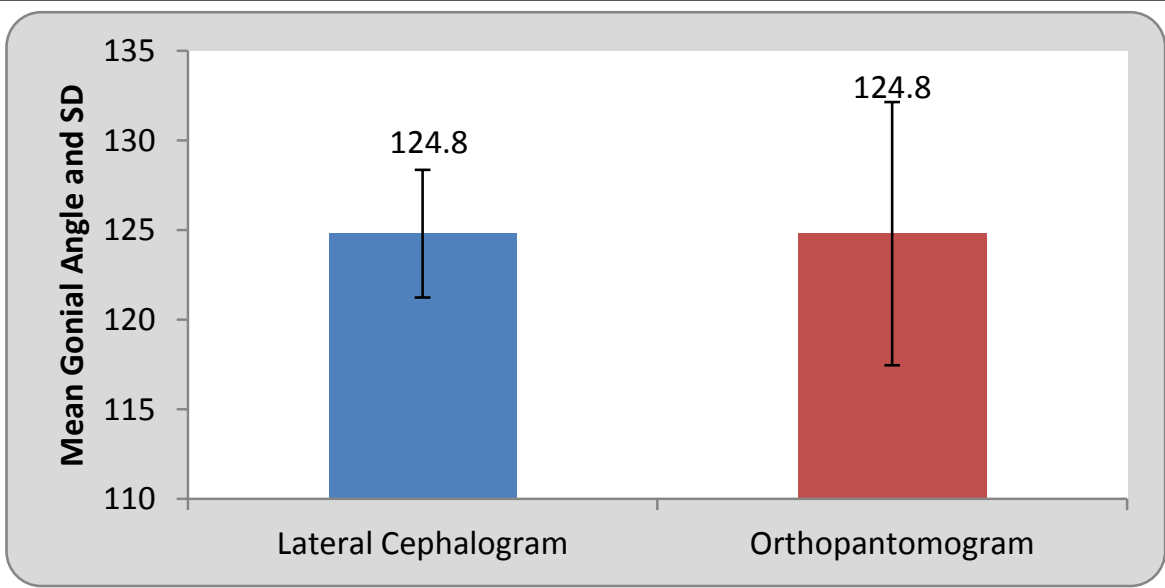


Mean gonial angle on right and left side of Orthopantomogram it was 123.24 and 123.24. By using Student's paired t test, statistically no significant difference was found between mean gonial angle by Orthopantomogram $(t=0, p=1.00)$ [Table III, Graph III]. anterior teeth of the lower jaw. ${ }^{6,7}$

This study is performed to assess and compare the measurements of the gonial angle from panoramic radiograph and lateral cephalogram. The use of panoramic radiography in the determination of the

Table III : Comparison of left and right side in class I and Class II malocclusion

\begin{tabular}{|c|c|c|c|c|c|}
\hline \multicolumn{7}{|c|}{ Orthopantomogram } \\
\hline & $\begin{array}{c}\text { Site of } \\
\text { measurement }\end{array}$ & Mean & N & Std.Deviation & Std .error \\
\hline \multirow{2}{*}{ Class I malocclusion } & Right & 123.24 & 25 & 7.77 & 1.55 \\
\cline { 2 - 6 } & Left & 123.24 & 25 & 7.77 & 1.55 \\
\hline \multirow{2}{*}{$\begin{array}{c}\text { Class II } \\
\text { malocclusion }\end{array}$} & Right & 124.80 & 25 & 7.34 & 1.46 \\
\cline { 2 - 6 } & Left & 124.80 & 25 & 7.34 & 1.46 \\
\hline
\end{tabular}

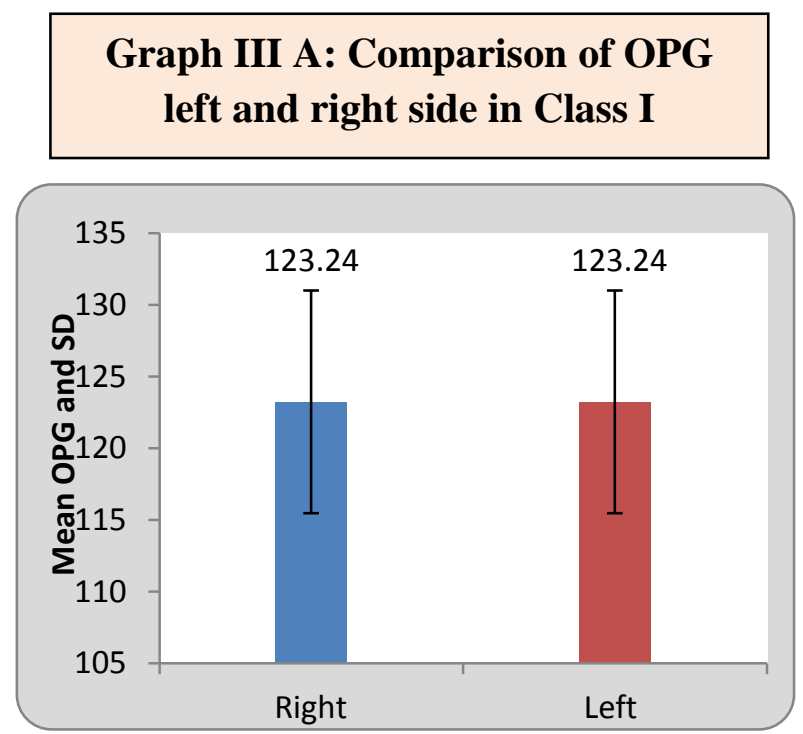

\section{DISCUSSION}

The gonial angle is one of the most important measurements required for Orthodontic Treatment and orthognathic Surgery. The gonial angle is also a representation of the form of the mandible. This angle has an important role in predicting growth, and it also has specific effects initially on the growth, profile changes, and the condition of the

\section{Graph III B: Comparison of OPG left and right side in Class II}

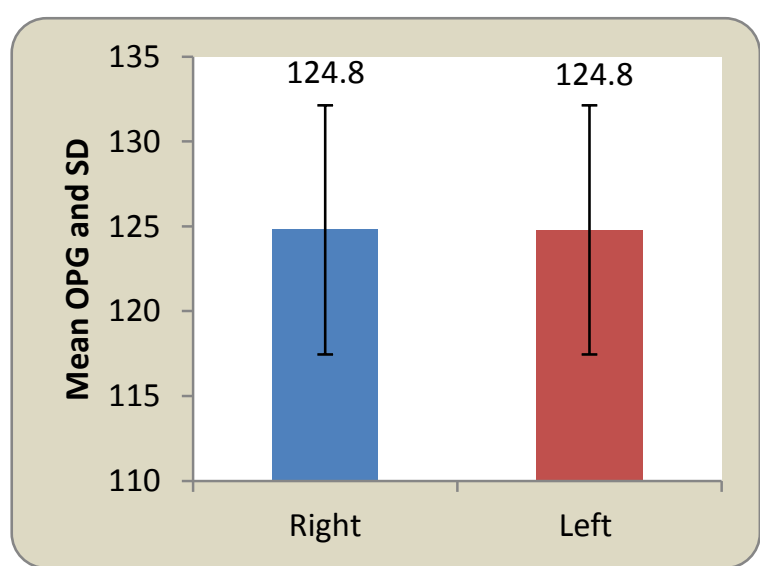

gonial angle has been studied and the results have shown that the gonial angle measurement on the panoramic radiograph is an accurate method.

Panoramic radiography has been reported to have potential in measuring mandibular inclination and gonial angle. It has been successfully used for determining gonial angle, which is a good indicator of mandibular steepness and growth direction. 
Because dentists routinely request OPG during dental examination, for determining growth direction, they can also detect the vertical growth problems. ${ }^{8}$

The results of the study demonstrate that there is no statistically significant difference in the values of gonial angle measured in Cephalogram and Orthopantamogram. Therefore, it is possible to use Orthopantamogram for measuring the gonial angle with accuracy as Cephalogram. It is desirable to make the gonial angle measurement on Orthopantamogram as both right and left gonial angles can be viewed separately and clearly on the Orthopantamogram. This fact is significant in the study conducted by Mattila et al. ${ }^{9}$ they took measurements of gonial angle on Cephalograms ,orthopantamogram and dried skulls and concluded that the measurements on OPG for right and left gonial angles conform to the angles measured on dry skulls. They further concluded that means of the measurements made on Cephalogram and Orthopantamogram show that the measurements made on Orthopantamogram are more accurate. ${ }^{9}$

The present study shows the same result. But the gonial angle measurement are routinely made on Cephalogram rather than Orthopantamogram.

The results of the present study demonstrate that OPG can be used to make these measurements as often as lateral cephalograms, especially in cases where the outlines of two sides are not clearly visible and in asymmetry cases before PA cephalograms are taken.

The present results are substantiated by Larheim and Svanaes (1986) and Akcam et al. ${ }^{10,11}$ In this study, we also compare the gonial angle in Class I and Class II malocclusion. In Class I malocclusion mean gonial angle by lateral cephalogram was $127 \pm 7.39$ and Orthopantomogram it was $123.24 \pm 7.77$ it shows no statistical significant difference found. In Class II malocclusion the mean gonial angle in lateral cephalogram 124.80 33.56 and in orthopantomogram it was $124.80 \pm 7.34$ respectively, with no statistically significant difference found.

Shahabi et al. Compared the external gonial angle determined from the Lateral Cephalogram and Panoramic radiographs in Class I patients. Based on the obtained results, they concluded that panoramic radiography can be used to determine the gonial angle as accurately as a lateral cephalogram. ${ }^{4}$

\section{CONCLUSION}

Panoramic radiography can be used to determine the gonial angle as accurately as a lateral Cephalogram as there are no significant differences in the gonial angle values as measured on cephalogram and OPG. And also there is no stastistical significant difference in the gonial angle values measured in Class I and Class II malocclusion. In addition, OPG forms an additional tool for easier and more accurate determination of both right and left gonial angles of a patient without interferences due to superimposed images of anatomical structures in a lateral Cephalogram.

For determination of the gonial angle, an OPG may be a better choice than a lateral Cephalogram. Thus, the present study substantiates the possibility of enhancing the clinical reliability of the panoramic radiograph, which is an indispensable tool for orthodontic diagnosis.

Financial support and sponsorship: Nil.

Conflicts of interest: There are no conflicts of interest

\section{REFERENCES}

1. Katti G, Katti C, Karuna, Shahbaz S, Khan M, Ghali S. Reliability of panoramic radiography in assessing gonial angle compared to lateral cephalogram in adult patients with Class I malocclusion. J Indian Acad Oral Med Radiol. 2016;28(3):252-5. 
2.Kundi I. Accuracy of Assessment of Gonial Angle by both Hemispheres of Panoramic Images and its comparison with Lateral Cephalometric Radiographic Measurements. J Dent Heal Oral Disord Ther. 2016;4(4):2015-7.

3.Okşayan R, Aktan AM, Sökücü O, Haştar E, Ciftci ME. Does the panoramic radiography have the power to identify the gonial angle in orthodontics? Sci World J. 2012;2012.

4. Shahabi M, Ramazanzadeh BA, Mokhber N. Comparison between the external gonial angle in panoramic radiographs and lateral cephalograms of adult patients with Class I malocclusion. J Oral Sci. 2009;51(3):425-9.

5. Zangouei-Booshehri M, Aghili H-A, Abasi M, Ezoddini-Ardakani F. Agreement Between Panoramic and Lateral Cephalometric Radiographs for Measuring the Gonial Angle. Iran J Radiol. 2012;9(4):178-82.

6. Nejad AM, Jamilian A, Meibodi SE, Hafezi L, Khosravi S, Cappabianca S, Perillo L. Reliability of panoramic radiographs to determine Gonial and Frankfurt mandibular horizontal angles in different skeletal patterns. Stomatology Edu Journal. 2016:81-5.

7. Abu-Taleb NS, El Beshlawy DM. Mandibular Ramus and Gonial Angle Measurements as Predictors of Sex and Age in an Egyptian Population Sample: A Digital Panoramic Study. J Forensic Res. 2015;06(05).

8. Bhullar M, Chachra S, Kochhar G, Kochhar A, Uppal A. Comparison of gonial angle determination from cephalograms and orthopantomogram. Indian J Dent. 2014;5(3):123.

9. Mattila $\mathrm{K}$, Altonen $\mathrm{M}$, Haavikko $\mathrm{K}$. Determination of the gonial angle from the orthopantomogram. Vol. 47, Angle Orthodontist. 1977. p. $107-10$.
10. Larheim TA, Svanaes DB. Reproducibility of rotational panoramic radiography: Mandibular linear dimensions and angles. Am J Orthod Dentofac Orthop. 1986;90(1):45-51.

11. Akcam MO, Altiok T, Ozdiler E. Panoramic radiographs: A tool for investigating skeletal pattern. Am J Orthod Dentofac Orthop. 2003;123(2):175-81. 